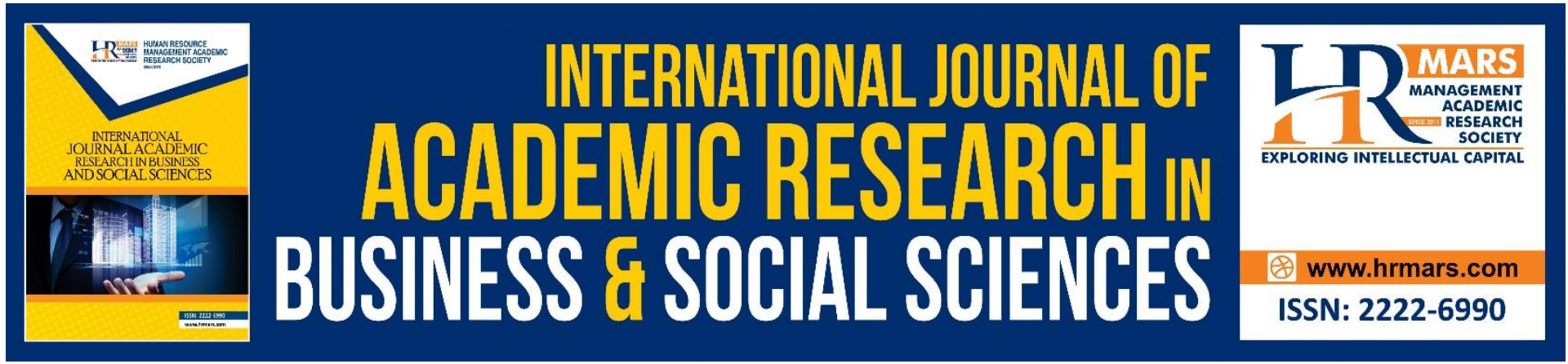

\title{
Elder Financial Abuse Experience: A Qualitative Study from the Perspective of Older Persons in Malaysia
}

Nurfadhilah binti Che Amani, Rojanah binti Kahar, Rahimah binti Ibrahim and Muslihah binti Hasbullah

To Link this Article: http://dx.doi.org/10.6007/IJARBSS/v11-i8/10409

DOI:10.6007/IJARBSS/v11-i8/10409

Received: 17 June 2021, Revised: 20 July 2021, Accepted: 01 August 2021

Published Online: 14 August 2021

In-Text Citation: (Amani et al., 2021)

To Cite this Article: Amani, N. binti C., Kahar, R. binti, Ibrahim, R. binti, \& Hasbullah, M. binti. (2021). Elder Financial Abuse Experience: A Qualitative Study from the Perspective of Older Persons in Malaysia. International Journal of Academic Research in Business and Social Sciences, 11(8), 479-498.

Copyright: @ 2021 The Author(s)

Published by Human Resource Management Academic Research Society (www.hrmars.com)

This article is published under the Creative Commons Attribution (CC BY 4.0) license. Anyone may reproduce, distribute, translate and create derivative works of this article (for both commercial and non-commercial purposes), subject to full attribution to the original publication and authors. The full terms of this license may be seen at: http://creativecommons.org/licences/by/4.0/legalcode

Vol. 11, No. 8, 2021, Pg. 479 - 498

Full Terms \& Conditions of access and use can be found at http://hrmars.com/index.php/pages/detail/publication-ethics 


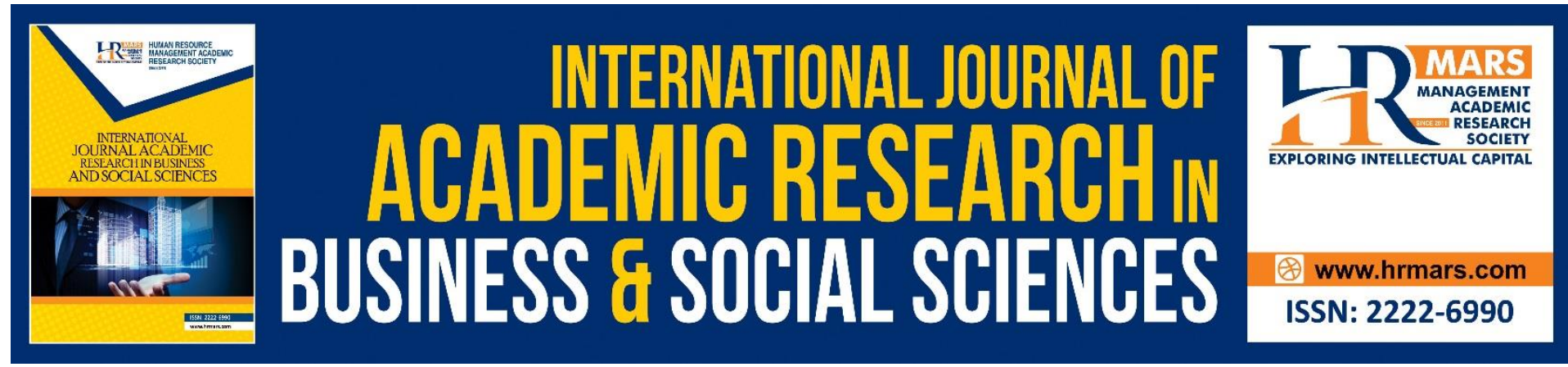

\title{
Elder Financial Abuse Experience: A Qualitative Study from the Perspective of Older Persons in Malaysia
}

\author{
Nurfadhilah binti Che Amani ${ }^{1}$, Rojanah binti Kahar², Rahimah \\ binti Ibrahim²and Muslihah binti Hasbullah² \\ ${ }^{1}$ Faculty of Syariah and Law, Universiti Sains Islam Malaysia, 71800 Nilai, Negeri Sembilan, \\ Malaysia, ${ }^{2}$ Department of Human Development and Family Studies, Faculty of Human \\ Ecology, Universiti Putra Malaysia, 43400 Serdang Selangor, Malaysia \\ Email: fadhilah.amani@usim.edu.my,rojanah@upm.edu.my, imahibrahim@upm.edu.my, \\ muslihah@upm.edu.my
}

\begin{abstract}
The underreporting incidents of financial exploitation of older persons committed by family members in Malaysia is a genuine concern. This study explores older adults' experience of financial abuse by family members, the dynamics of their relationship, and how older people respond to this experience in Malaysia. The study was conducted using a phenomenology study design via in-depth interviews of eight older adults who were purposively sampled using snowball sampling. NVivo 12 analysis software was used to perform the thematic analysis. Seven main themes were identified: cultural expectation and tolerance of abuse, negative well-being, family comes first, helplessness, coping strategies, positive reappraisal, and selfreflection. The themes demonstrate the interactions among the components of experiences of older adults coping with financial abuse by family members and how they chose to respond. The results reveal the inadequacy of protections available to older adults in Malaysia in the reporting process, laws, and policy. These results suggest for authorities to consider dilemmas faced by older victims of financial abuse, especially with regard to underreporting. A clearer understanding of social realities will help improve social and legal protection frameworks for victims of financial abuse involving family members in Malaysia.
\end{abstract}

Keywords: Elder Financial Abuse, Financial Exploitation, Elder Abuse, Aging, Older Adults

\section{Introduction}

The World Health Organization (WHO) has recognized financial abuse as a type of abuse experienced particularly by older people (Price et al., 2011). They define financial abuse as the "illegal or improper exploitation or use of funds or other resources of the older person" (WHO, 2002, p. 3). Elder financial abuse is understood as such conduct being committed against an individual who is 60 years of age or older. Though the definition of older person differs from one country to another, in most countriesit is usually retirement age. 
Financial abuse is present in both rural and urban areas in Malaysia. Based on a report from a longitudinal study conducted in 2016 that focused on a rural area in Kuala Pilah, in the state of Negeri Sembilan, financial abuse was reported as the second most common form of abuse among its residents (Yunus et al., 2017). In a pilot study conducted with urban poor in Kuala Lumpur, it was found that $6.2 \%$ of older people had experienced financial abuse, making it the most common type of abuse after psychological abuse among the elder (Sooryanarayana et al., 2017). Reports have shown the limited availability of data regarding abuse and neglect of older people and the high probability that the number increases every year (Ahmed et al., 2016; Bidin \& Yusoff, 2015).

The notion that elder abuse cases are underreported resonates in the literature (Dessin, 2003; Moskowitz, 1998; Rabiner et al., 2004). Financial abuse or exploitation incidents, in particular, create even more difficulties in detection and reporting There seems to be a consensus in the literature that differentiates the types of perpetrators and the chances that incidents will be reported. The stronger the relationship (a person in a position of trust) between victim and perpetrator, the lower the chances that an incident will be reported (Met Life Study, 2010; Jackson \& Hafemeister, 2015; Miskovski, 2014). Further, it emphasizes that, if there are no ties between perpetrator and victim, the more likely an incident is to be reported. Complicated reporting mechanisms worsen the situation for both thevictims and experts in the field of elder abuse (Miskovski, 2014), and complex family dynamics can increase the reluctance of witnesses or victims to report financial exploitation of older persons by family members. Among the contributing factors are mutual dependency (Dessin, 2000), fear (Kaspiew et al., 2016; Rabiner et al., 2006), and cultural expectations (Kaspiew et al., 2016). Emotional stress resulting from the consequences of reporting increases hesitation to notify the authorities. Other factors, such as lack of awareness of rights and entitlements (Kaspiew et al., 2016; Doron et al., 2004) and poor wealth management (Setterlund et al., 2007), can lead to the refusal of older persons to disclose incidents of financial exploitation.

The implications for older persons who are victims of financial exploitation must be highly emphasized. A two-year population-based study to measure mortality rates among older Malaysians living in rural areas discovered that death rates were second highest (13\%) among targets of financial abuse, only after those who were victims of psychological abuse (Yunus et al., 2017). Kaspiew, Carson and Rhodes (2016) and Bagshaw, Wendt, Zannettino, and Adams (2016) highlight how financial abuse of older persons suffered depletion in their wealth, experience psychological trauma, and exhibit a decline in quality of life.

Ignoring the problem could cause adverse effects for future members of the older population. Looking at Malaysia's demographic transition, as of 2018 the total population had increased from 31.7 million to 32.4 million, of which $15.3 \%$ are over 60 years of age (Department of Statistics, Malaysia, 2018). The demographic data are in line with the United Nations World Population Ageing Report (2015), which showed that the growth of the population over 60 years had been accelerating in developing regions. It is clear that the social phenomenon of elder financial abuse deserves immediate attention to understand the reality of such financial exploitation by family members.

Through qualitative investigations, this study collected the views of older people to better understand how they make sense of their experience with financial exploitation. The study also explored the nature of the relationship they have with family members. This approach will provide a deep, contextualized understanding of financial exploitation within the local context. Understanding the lived experience of older Malaysians who were victims of elder 
financial abuse may promote greater understanding among policy makers for developing effective prevention and intervention measures to eradicate the problem.

\section{Materials and Methods}

This study adopted the qualitative phenomenological approach. This method of inquiry explores human experience and searches for the meanings that people make from their lived experiences (Creswell \& Poth, 2018). Creswell and Creswell (2014) stated that qualitative research begins with assumptions and the use of an interpretive/theoretical framework that informs the study of research problems addressing the meaning that individuals or groups ascribe to social or human problems. It is the nature of a qualitative researcher to "make sense of, or interpret, phenomena in terms of the meaning people bring to them" (Denzin \& Lincoln, 2011). It is important that data should be collected in a natural setting and be sensitive to the people and places under study. The inductive data analysis process generated a pattern or themes for this study. The final report reveals the voices of the participants, the reflexivity of the researcher, and interpretation of the problem.

\section{Participants and Setting}

The study adopted purposive and snowball sampling for participant selection to enable the gathering of rich and detailed information on the above research questions. The criteria for participant selection were as follows: (1) the older person experienced some form of financial exploitation by their family members, (2) the older person was at least 60 years of age, and (3) the older person must not suffer from any cognitive impairment. The questions for the interview included demographic data, such as age, sex, previous occupation, source of income, medical condition, living arrangement, current relationship status, and number of children, as well as the form of financial exploitation experienced. This study did not require participants to be in an institutional setting or living in an organized community because, although financial exploitation incidents occur within residential homes, based on the literature, the implications of such incidents may alter the living arrangements of the older persons. The in-depth interviews were conducted face to face. The interviewer utilized a predetermined set of interview questions. Average interview length was 40 minutes to 1 hour, and the interviews were held at a location that was convenient for the participants.

\section{Data Collection and Analysis}

In this study, participants were identified to have experienced any act of financial abuse by family members since turning age 60 years. Participants responding positively or giving insight into financial abuse incidents were seen as an indicator that they had experienced a financial abuse incident at least once in their lives. These participants were invited for a further indepth interview. To ensure that participants were not cognitively impaired, the study included an initial screening of the cognitive ability of participants conducted using the Elderly Cognitive Assessment Questionnaire. This questionnaire was developed to assess cognitive impairment among elderly people in developing countries and has been validated for use with the local population in this study (Sherina et al., 2004). During the interviews, responses to the open-ended questions by the participants were recorded using audio devices (with permission obtained), observations, and field notes. Immediately after the completion of each interview session, the audio tapes were transcribed and verified with the field notes to ensure that the interviewer had a full understanding of the content within the context of the participants' perspectives. Raw data were transcribed into text. Codes were analytically 
developed or inductively identified in the data and affixed to sets of notes and transcript pages. These codes then were organized into categories and labels. This process utilized computer analysis of qualitative data using NVivo. Validation of data findings was done through the processes of triangulation, member checking, and external audit.

\section{Findings}

A total of eight participants completed the interviews. As shown in Table 1, participants' ages ranged from 61 to 86 years. There were five female participants and three male participants. Most identified as Muslim, while only one participant identified as a Hindu. The race of the participants included five Malays, two Indians, and one Chinese. The marriage status of the participants was three widows, one not married, and the rest divorced. None of the participants had graduated at the tertiary level. Only two participants had completed high school, and the rest did not finish primary school. Most of them described their overall physical health as healthy and moderate with normal old-age illnesses. Their current place of residence was mostly living in welfare homes or paid care centers. Only two of the participants lived in their own home. Each interview was recorded, and those recordings, together with the other data, produced findings that were used to answer the research questions. The results revealed that participant's views included both positive and negative components. The participants accentuated their experience with financial exploitation by family members through the following themes: (1) "cultural expectations and tolerance of abuse," (2) "negative well-being," (3) "family comes first," (4) "helplessness," (5) "coping strategies," (6) "positive reappraisal," and (7) "self-reflection."

\section{"Cultural Expectations and Tolerance of Abuse"}

The participants had all tolerated the financial abuse in some way, due to culture or family practice. It is interesting that tolerance was practiced from multiple angles by the participants. Some participants expected and tolerated the attitudes of family members because of an existing parent-child relationship and cultural expectations. P1 was pressured by her son and reluctantly decided to create debts on his behalf because she felt that caring for him was partly her responsibility as a mother. P4 shared similar motherly feelings when she tolerated and met her adult child's demands and generously gave out money to her adult son with full knowledge that it would be detrimental to her financial situation. P3 embodied this experience by believing that he was a burden to his own family due to his disability. He tolerated the unauthorized withdrawals made to his account by his adult son. P7 tolerated the stealing of jewelry and being deceived by her siblings, who withdrew her life savings, due to her dependency on those family members.

\section{"Negative Well-Being"}

The participants portrayed how the financial exploitation experience had affected them in different aspects of their life. Evidence of a decrease in quality of life after being a victim of financial abuse included financial insufficiency, disturbed emotions, and a decline in their physical and social health. P4 confessed that she does not have enough savings for old age. At 61 years of age, she could not enjoy her savings or hard-earned money, and her expectation for her daughter to pay her debt was also unmet. Negative well-being was also described by P6, who made the needs of her grandchildren the main priority despite her unstable income. Caring for four grandchildren affected her livelihood, especially her physical and mental health. P2 expressed his sadness about his lack of savings resulting from the deceitful financial 
arrangement with his brothers that led to him residing in a shelter home. Negative well-being also revealed emotional pain and psychological trauma experienced by the participants. P3 expressed feelings of extreme anger toward his children for taking his money without permission. P7 suffered severe trauma and depression and was forced to leave her house after all of her money and jewelry was stolen by her siblings. Negative well-being includes social isolation resulting from being removed from the environment in which the participants lived. P2 missed his friends and his house after moving to a shelter house. P1 described that she had to deal with negative judgments and stigmas from her relatives when she borrowed money from them to meet the unnecessary demands of her son, and she had broken all relationship ties until all loans were fully paid. P5 admitted that her social life, for example, traveling and religious activity at the mosque, needed to be put on hold because all of her focus was placed on tending to the needs of her grandchildren. Being a victim of financial exploitation has resulted in low self-worth, and the participants believed that it had lowered their social status in the community. P3 and P2 believed that it has become a norm within society that you need to have something to offer to be treated nicely. Participants also shared the common experience of how a decline in physical health has affected them after experiencing elder financial abuse by family members.

\section{"Family Comes First"}

The third theme evidenced how older people give meaning to the financial abuse experience by upholding the value of family preservation. This value has been the central idea that binds older people to their family. Almost all participants' stories had elements in common, particularly putting their family first in all financial abuse circumstances. P1 believed that borrowing money from her siblings to meet the unnecessary demands of her adult son was putting her family first. P2 described his act of lending money to his siblings as family sacrifice. P4 felt that she had to continue parenting her adult children, believing that they still needed her help due to their unstable employment. P5 mentioned that she needed to be the parent for her grandchildren because their own parents were not capable of raising them. This theme also resonates with the way that participants managed their responses to the financial abuse incidents when they were asked why they chose to keep silent.

\section{"Helplessness"}

The fourth theme gathered from the data is helplessness. Helplessness in this context is best described as how participants were unable to defend or remove themselves from being in the environment of financial exploitation by family members. Helpless conduct was experienced in various situations. First, the participants described the limited options available to them in their contextual situation that made them vulnerable as victims. In most cases, the participants depended on and trusted the perpetrators. P4 described how she lived with her daughter and son-in-law, and how her frequent contact with her adult sons made her vulnerable to the act of "borrowing money" by her children. P7 described how being an older woman, unmarried and uneducated, made her socially isolated from other people; her high dependency on her family made her an easy target. P6 explained that, after the death of his wife, he depended on his relatives because of his poor health condition. P8 also expressed that, since she is childless, after the death of her husband she had no one to care for her except for her niece.

Second, the participants expressed how they were trapped in the environment during the financial abuse incidents. They elaborated that, when they were asked how they dealt with 
situation, some agreed that they felt conflicted. This was even more true if the perpetrator involved adult children. This can be seen when participants either refused or were reluctant to disclose such incidents to other people. Some would only feel comfortable telling close friends, and they accepted that nothing could change their fate. Participants expressed that they would feel guilty if their loved ones were punished for the incident. P7 described how she preferred to forgive when her social worker tried to persuade her to press charges against her siblings for stealing. She believed that reciprocal legal punishment is not the best solution, and such an action would make her no different than her abuser. P8 felt that, in a situation where she has been victimized, even if reports were made, the remedy available is not sufficient for asset recovery. Participants also shared the complicated procedure for reporting and expressed concern about the cost of legal action. Helpless feelings were also expressed when participants faced negative comments and judgments by other people for being a victim of financial abuse by their own adult children.

\section{"Coping Strategies"}

Participants were asked how they responded to the financial abuse experience, and their responses revealed conflicting judgments that they made in response to the incidents. When participants were given a hypothetical situation of an older person being a victim of financial abuse by their own family members, seven out of eight participants felt that the most appropriate thing to do was to report the incident to the authorities. However, when participants were asked how they responded to their own experience, most opted for alternative solutions, for example, educating and creating awareness among the younger generation. Though P3 expressed how he was disappointed with his children, he blamed himself for what happened. He believed that self-blame was the easiest way to accept the situation. P8 blamed her niece and believed that her niece did not have pure intentions in their relationship. She felt that her niece had always been after her property. Thus, putting the blame on her perpetrator made it easier to cope with the situation. P4 assured herself that she was helping out her adult children in order to be accepted by them. The lack of a support system encouraged a systemic response by the participants. They tended to blame themselves or blame others for what happened, and they had no avenue to go down for support in dealing with their problem.

\section{“Positive Reappraisal”}

Positive reappraisal is an adaptive process by which stressful events are reconstrued as benign, valuable, or beneficial. This involves one's belief and value systems. Belief and value systems are mostly influenced by one's religion, traditions, and culture. P4 endured her experience by accepting that it was fate and ordained by God. She believed that living with contentment and gratitude was the way to move forward. Similarly, P3 believed that his experience was the result of God's will. He felt that it was easier to accept fate with grace, rather than blaming others or the system. P5 explained her experience by highlighting the importance of hope and faith in God. She mentioned that she really believed that she could feel God's presence surrounding her when she received assistance from other people, and she sought relief from God. When P8 was asked why she did not disclose her niece's conduct to authorities, she answered in a simple but meaningful way: that it is better to let go and focus on the afterlife. 


\section{"Self-Reflection"}

Participants processed financial abuse by family through personal reflections. P4 remembered how her neighbor was once a victim of financial abuse by her daughter. She knew that some people in her community had experienced elder financial abuse, but she chose not to do anything about it. When asked why, she responded that it would be an invasion of privacy. P1 remembered how her experience taught her a lesson to prioritize herself. That experience taught her to educate her children on financial responsibility. Most participants mentioned the importance of empowering older people in financial literacy. P3 mentioned that he learned not to trust other people in managing financial affairs. P3 wished that other older people would learn the lesson he did. Empowering older people to be financially independent was a goal that was also shared by P7 and P2. P7 hoped that fellow older people would learn from her mistake and not become victims. P2 also wished that older people would practice financial prudence. He believed that, at the end of the day, nobody but yourself will help you in the event of financial difficulty. Participants also mentioned that they were uncertain of their future. Fear of the future, for P4, meant anticipating her adult children's future without her financial support. Similarly, for P5, fear of the future meant that she wondered who would take care of her grandchildren when she is no longer around.

\section{Discussion}

This study adds to the limited research that explores elder financial abuse among Malaysians. Some may regard this social problem as not deserving greater attention due to the limited number of cases reported. However, the approach of "no news is good news" does not reflect the social realities of the elder financial abuse phenomenon in Malaysia. The present study discovered critical matters that need urgent review to improve social and legal protection frameworks for victims of financial exploitation cases involving family members.

This study's findings reinforce the literature on the complicated family dynamic between victims and perpetrators that greatly influences how victims experience and deal with these incidents. Cultural expectations and tolerance of abuse described how participants felt trapped in an environment where they were expected to tolerate an act of financial abuse under the pretext of culture, tradition, and valued role expectations rooted in the deep values of the family. The complex interpersonal relationships between the perpetrators and the older victims are usually culturally constructed. These results are corroborated in the literature on the importance of cultural context and interpersonal relationships, which are normally culturally constructed in the Asian population (Tan et al., 2020; Yan et al. 2014).

Tolerance of the financial abuse often caused the victims to suffer financial burdens, though they failed to view it as such because of the bond they share with their children. Different views on the act of borrowing money were discussed in Milhaljsic and Lowndes (2013), and they illustrate how the attachment bond and types of relationships influenced how older people treated the act of giving a loan; many gave with the expectation of not being repaid, especially if the loan was to their own children (Milhaljsic \& Lowndes, 2013). This was supported by research conducted in the United States among Korean elderly immigrants, where adult children taking money without their elderly parents' permission or choosing not to repay borrowed funds was the second most common definition of financial abuse (Lee et al., 2012; Chang \& Moon, 1997). In the present study, tolerance by the participants of the unnecessary demands by their adult children or siblings showed how participants were left with no choice but to believe that such behavior was expected of them in exercising their duties as parents or older siblings. 
Jervis et al (2017) discussed how inappropriate demands by adult children, especially related to childcare and have emerged as salient concerns. Adult children are believed to exploit their older parents by draining the financial resources in raising grandchildren. A study of Native elders explained how culturally prescribed and valued role expectations, which include close relationships between grandparents and grandchildren, cloud their judgment. The Native elders who provide for their family while ignoring their own needs do not see such acts as abusive (Jervis et al., 2017). Culture in Serbian families is also influenced by strong patriarchal ideology where parents are expected to sacrifice their own needs to support their children; this is especially true for women who are expected to devote their lives to caring for their grandchildren (Petrusic et al., 2015). This culture of self-sacrifice has contributed to the low recognition and reporting of elder financial abuse in Serbia. This study also revealed how participants expressed their high tolerance for financial abuse due to their dependence on their family members for their living arrangements and assistance. The high tolerance of elderly parents toward their adult children's aggressive and demanding behavior involving monetary abuse was related to their feelings of guilt and their obligation to provide financial assistance to their adult children and grandchildren (Bagshaw et al., 2013). High tolerance in an abuse situation also reflects the desire of parents to protect their offspring regardless of the adult children's abusive behavior (Bagshaw et al., 2013; Jackson \& Hafemeister, 2015). The findings of this qualitative study showed that participants experience a low quality of life resulting from the financial-abuse experience. The negative impacts described by the participants included limited financial means, emotional stress, poor social interaction, and declining physical health, and some participants were even neglected or abandoned by their family members. Rabiner et al (2004), in developing the conceptual model for financial abuse, discussed how financial abuse of older persons had long-term effects on them, especially on the emotional well-being of the victim and the perpetrator, the durability of the caregiving relationship, and the victim's sense of security and trust. It is also important to consider the suggestion by Sanchez (1997) that the effect of financial exploitation on an older victim may have a greater impact in the long run. Financial implications may also include older people's ability to be mobile and independent, and their limited purchasing power, which is vital for their livelihood. According to Yunus et al. (2017), this may have contributed to the increase in cases where victims experience deteriorating living conditions and the worsening of an existing illness or even death. The worsening of an illness may have negative implications for the victim's physical well-being.

Often, financial exploitation is also associated with self-neglect and emotional abuse (Mardan et al., 2014). Emotional effects can appear in the form of embarrassment, stigmas, and psychological trauma (Rabiner et al., 2005; Dessin, 2000). According to Dong et al (2011), Chinese older adults may hold higher emotional expectations based on their traditional belief in the filial system. Thus, they may be more prone to emotional distress. According to Barjose and Aranas (2016), a study conducted by the Hong Kong Christian Service (2004) found that many participants expressed how shameful it was for them to disclose to other people the abuse by their own children. They felt that certain matters may be regarded as private and must not be known to other people in order to "save face." Hightower et al (2006) emphasized how emotional repression built up within victims of abuse who did not manage to reap the benefits of their older age; after building their lives, raising children, and establishing a home, they had to completely restart their life as a victim of abuse.

The study also discovered that participants' well-being was reduced by having to spend their old age in a shelter home, mostly drained of financial resources because of the financial 
exploitation by family members. This was evidenced in studies where social losses were described as leaving a neighborhood and community that had been part of their life. The relationships with family members were broken, often out of fear of vengeance, and the older victims could no longer be part of the community due to their need to separate from their family members (Hightower et al., 2006). This was supported in research that found that victims will question their own financial capabilities and may suffer stress and be isolated from family and friends (Deem, 2000); worse, financial exploitation victims may suffer from depression, hopelessness, or even consider suicide (Nerenberg \& Goldman, 1999; Rabiner et al., 2004). This study also illustrated the complicated nature of relationships between the participants and the perpetrators. These interactions directly influenced the participants' experiences and how they responded to the financial abuse. The nature of the relationship and the family dynamics between the victims and their relatives has become inextricably intertwined as factors in elder financial abuse (Jackson \& Hafemeister, 2015; Rabiner et al., 2005; Dessin, 2000).

Almost all participants in the present study shared the experience of putting family before their own needs. This act was reflected in their experience which involves relationship of trust, dependency, family expectations, and isolation. Further, relationship dynamics between perpetrator and victim could also be assessed by looking at the unequal status of perpetrator and victim, patterns of interaction over time, and the reciprocal nature of their relationship (Conrad et al., 2010; Kemp \& Mosqueda, 2005; Rabiner et al., 2004; Wilber \& Reynolds, 1997). The practice of putting family first was discovered in various localities and populations, as illustrated in many studies. Aborigines in Australia emphasized sharing resources among familial and community networks (Kaspiew et al., 2016). Financial transfers and gifts from parents to adult children are considered normal occurrences and, in some situations in Mexican culture, they are expected (Moon \& Benton, 2000; Sanchez, 1997). Jarvis et al (2017) found that Native elders experienced clouded judgment in situations where they were asked to provide for the families. They did not see this act as abusive, even if it would cause them to deprive themselves and deny their own needs. Similarly, in a study in Australia, older people seemed to accept the illegal practice of family members being their asset managers; reasons included family loyalty, needing assistance, and social isolation (Setterlund et al., 2007). Women in Serbia were expected to devote their time in old age to care and provide support for their grandchildren, including taking responsibility for household chores in their adult children's home. This sort of attitude, known as a culture of "selfsacrifice," may be contributing to the low reporting and low recognition of financial abuse in Serbia (Petrusic et al., 2015). Jervis et al (2017) argue that, in the literature, family sacrifice may be rooted in long-standing traditional practice in a particular society. The idea of putting family first embraces the "family preservation" principle. This was explained by Weiner (1991), who stated that family preservation is the main priority, and there is a lack of reporting or disclosing elder abuse in rural communities in order to avoid shame. The findings revealed that it is easier to prosecute non-related perpetrators because no emotional investment was involved, as compared to cases that involved family members. Evidence of family preservation was also provided in Phelan et al (2018). The success of a case involving elder financial abuse is determined by the relationship between the perpetrator and victim. Often, case resolution fails when the older person wishes to sustain the relationship they had with the perpetrator. The most striking result to emerge from the data is that older people felt helpless and powerless in their experience with financial exploitation by family members. The findings provide evidence that the state of helplessness was observed among all participants. 
Participants displayed helplessness in one of two contexts: first, the situational context, and second, the lack of a support system for seeking help with financial abuse. Situational factors, such as old age, social isolation, extreme dependence and frailty, severe mental and/or physical illness, being a widowed female, and low financial management skills, raise the chances of elder financial exploitation (Acierno et al., 2010; Dessin, 2000). From the present study, participants displayed situational factors, such as dependency, co-residence, and cultural expectations. With no reciprocal exchanges transferred from older parents or adult children in relation to caregiving activities or financial assistance, status inequality may prevail and increase the chances of abuse (Kaspiew et al., 2016). This study supported earlier work conducted in Australia where the risk factors for abuse of the participant by her adult son increased with her dependency on her son, as well as her son's sense of entitlement to her properties and other assets (Wendt et al., 2015; Bagshaw, 2013). Situational factors can contribute to the vulnerability of older persons, particularly when they are related to the advancement of technology, such as the use of online transactions, including internet banking and other electronic money-transfer methods (Rabiner et al., 2006). This finding also agrees relatively well with the observed lower chances of reporting abuse to avoid the withdrawal of care by family members (Jackson \& Hafemeister, 2015).

Lack of a support system for seeking help can be explained by inadequate legal protections available to the victims, which contributes to the silence and underreporting. Complicated reporting mechanisms were important where participants felt that their physical health and financial position limited them from completing the reporting process. The participants' worries about the ability to afford the expensive legal costs and the ability of family members to repay the economic loss have also been reported in past studies (Dessin, 2006; Lee et al., 2011; Dong et al., 2011). Research by Tilse et al. (2005) mentioned that legal redress is often unattainable. The other limitation that hinders victims from pursuing justice is the priority to maintain a relationship with the perpetrator; often, victims believe that this is more important than pursuing justice.

Another systemic failure in providing legal protection to victims of elder financial abuse is when the burden to prove an act of abuse must be borne by the victims. The detection of financial exploitation is not as easy as with physical abuse (Moskowitz, 1998). Financial exploitation is committed within private settings. Further, the admissibility of evidence given by old, frail, and sick victims is often challenged in court and doubted by other family members. Seagal and Doron (2019) posit that negative reactions from family members may intensify self-blame, loss of confidence, lack of energy, and helplessness. These behaviors can be termed "self-imposed ageism" (Doron \& Apter, 2010). It was observed that participants also felt helpless subsequent to the financial exploitation incidents. The findings provide evidence that lack of knowledge and a poor support system influence the refusal to disclose the act of financial abuse by family members.

Feelings of distress, often accompanied by a sense of guilt, created a dilemma for participants between tolerating the abuse and reporting it. Personal reasons, such as embarrassment, shame, fear, and a desire to maintain family dignity, were also relevant in assessing factors that reduced reporting by older persons (Rabiner et al., 2004; Dessin, 2000; Weiner, 1991). This dilemma was observed in the present study when participants displayed positive attitudes when asked about reporting financial incidents by family members as an appropriate solution for older victims, but chose to tolerate such incidents when they involved their own family members. This finding is consistent with research showing that women are less likely to report any situation of abuse because they hope to protect a family 
relationship or trust relationship, and resort to self-blame and keeping silent (Knight et al., 2016). A sense of guilt that was compromised by tolerance of the abuse always appeared in situations where an older person required assistance from their adult children and grandchildren (Bagshaw et al., 2013). Creating awareness among family members was a more preferable choice among the participants compared to reporting the incidents to the authorities. This was supported in a study conducted by Milhaljsic and Lowndes (2013). The older group preferred to intervene by creating awareness and educating the older people and adult children. Older Native Americans are more favorable toward reporting financial abuse cases if there is a court that specializes in elder abuse, especially one that addresses victim reimbursement (Knight et al., 2016).

This study agrees with the view that elder abuse mirrors the societal arrangements that give rise to the abuse (Chane \& Adamek, 2013; Mysyuk et al., 2013). Bealieu et al. (2015) highlight the importance of psychosocial support from the community, comprised of volunteers, police, community centers, and public social services; they also emphasis that a restorative justice lawyer should be made available to older people who are victims of financial exploitation. Seagal and Doron (2019) further suggest that positive social support from family members may influence a victim's willingness to reach out for professional help upon realizing that they have become a victim. This study discovered that, due to inadequate social support and the unpopularity of legal protections available to them, participants were indirectly forced to embrace "rationalization" and believing in the "higher power" as ways of coping with the financial exploitation. Victims expressed their feelings knowing that their finances were being deprived and used inappropriately by the perpetrators, but they claimed that, apart from being financially deprived, they did not suffer any other negative physical or psychological implications (Phelan et al., 2018). Similarly, victims of elder financial abuse by family members rationalized their adult children's conduct by pointing to their children's rights of entitlement over their assets or properties-in other words, that eventually the property will belong to them (Phelan et al., 2018; Wendt et al., 2015; Bagshaw et al., 2013). Therefore, in this case, positive reappraisal and rationalization helped participants to redefine the situation of financial exploitation in a more positive way; by doing this, they may have received benefits from their stressful experience (Folkman, 2011).

Believing in the higher power indicates how participants develop adaptive coping strategies through religion. This reflects how a group of women victims of abuse in Canada found peace through religion, decreasing the importance of the abuse in their lives. Religious faith has helped them to forget about the abuse act (in this life) and focus on their next life (Hightower et al., 2006). Harrison et al (2001) explain how religious coping can have positive effects on individuals' health, for example, positive psychological adjustment. Religious coping could be in the form of redefining God's powers to influence the stressful situation, redefining the stressor as a punishment from God for the individual's sins, engaging in religious activities to shift the focus from the stressor, seeking a sense of connectedness with forces that transcend the individual, and offering forgiveness through religion to let go of anger, hurt, and fear of others. This conduct was noted in the results where participants showed forgiveness, blessed feelings, kindness, and acceptance of their fate in their experience of financial exploitation. The results are in line with literature that found that self-esteem, life satisfaction, and quality of life have been associated consistently with positive religious coping (Koenig et al., 1998; Pargament et al., 1998). Participants also described their regrets and wish for empowerment of older people, including financial literacy and financial prudence, for a better future. They mentioned that it is vital for older people to be independent and practice self-love. 
Based on this study, the experiences of older financial victims were silenced by the systemic failure presented in the legal and social system relating to the rights and protections of the older person. Currently, the existing framework is inadequate to provide social and financial support to victims of elder financial abuse should they choose to disclose any act of financial abuse by their family members. The framework must be enhanced to ensure victims' physical and mental health are safeguarded, which includes providing a secure and safe environment should the victims require relocation, especially if the victims need care services. This study suggests several potential steps to address these problems.

First, at the policy level, laws that focus on elder abuse must be reviewed. For it to be effective, the laws must not only protect the older people but also be aged-friendly and family-friendly. From the perspective of criminal justice, at present, the legal protections available need to be revisited to strike a balance between justice for the older victims and maintaining family principles. Family is an emotional unit. Individuals cannot be understood in isolation from one another but, rather, as part of their family. Therefore, families are systems of interconnected and interdependent individuals, none of whom can be understood in isolation from the system (Brown, 1999). It is because of this that this study recommended revisions to existing legal provisions that govern domestic violence. Based on the participants' experience, putting your loved one in jail as punishment is not an option, as it defeats the purpose of the family system.

The present study revealed sub-themes, such as the "attachment bond," "family preservation," "distress," and "sense of guilt" as justifications for why older Malaysians hesitated to disclose the incidents to authorities. This can be explained by looking at the legal provisions available involving elder abuse and financial exploitation. For example, the lack of a mandatory reporting requirement in Malaysia contributed to the low number of reported incidents. Despite the fact that the main legislation on domestic violence (the Malaysian Domestic Violence Act of 1994) provides legal protection for any individuals to supply information relating to domestic violence to authorities, a lack of mandatory reporting means that there is no legal obligation for individuals to report the incidents. The process for obtaining protection orders was improved in 2017; specifically, the law was amended to allow victims of domestic violence to seek emergency protection orders, either by themselves or through their counsel or social welfare office, guardian, relative, or the person responsible for their care. However, with the mechanism in place, there also exists a practice gap for isolated or physically or mentally impaired victims who might have a harder time placing a call or visiting the Social Welfare Department to apply for the emergency protection order. More importantly, an alternative solution to legal proceedings must be made available to stop family members from continuing the financial abuse.

The present study allowed us to understand the victims' emotional dilemma of choosing between self-care, guilt, and breaking family ties. The victims' fear of the consequences of reporting is twofold. First, the repercussions of reporting include criminal charges and penalties for the family member who is the perpetrator. Second, reporting the abuse means losing a safe and familiar environment desired by the victims, which may result in uncertain living conditions and anxiety due to separation from their family. Supporting governmental and non-governmental organizations should develop programs which support older people who have been victims of abuse; these programs need to be thoughtfully designed to allow victims to enjoy a high quality of life after the abuse. The support program must offer a safe and secure environment for the victims to continue to practice active aging in their later years. A safe residence, old-age economic security, care support, and access to medical care and 
supportive community members must be available for older people to avoid stigmas and regain their confidence in society.

Second, the need to have first-responder teams of health and social service experts who can give immediate assistance in any suspected or substantiated cases of elder financial abuse may encourage victims or individuals to come forward and disclose any incidents in the community. These first-responder teams may be officers from the primary health care, social welfare, and banking services who have undergone training to screen for and detect any suspicious incidents of elder financial abuse. Presently in Malaysia there is no mechanism for professionals to monitor the financial conditions of an individual in the private sphere. Professionals, such as medical officers and those in the banking sector, are not legally obligated or trained to report conduct they suspect may be financial abuse. This could be due to a lack of guidelines and proper training (Gilhooly et al., 2013). In addition, culture and the traditional values of a particular society, which discourage people from intervening in family matters, explain why professionals, doctors, or banking officers found it difficult to manage any cases that raised a concern about financial exploitation by relatives. This may not be the case in a country that imposes mandatory reporting laws (Gilhooly et al., 2013). The firstresponder teams may also be counselors or members of religious centers in the community where victims have close interactions and social relationships. Dong et al. (2011) explained that the participants believe that a community service center would be a better place to seek help. This research also found a lack of awareness among the participants in regard to possible resources other than the police and the service center.

Third, the most fundamental step in preventing financial abuse by changing attitudes among social care professionals, as well as family members and older persons, themselves, is to raise awareness. This should be developed from the local or individual level, which can then inform organizational, national, and international policy (Wendt et al., 2015; Lowenstein, 2009). At the national level, raising awareness must include strengthening filial piety among the Malaysian younger generation. Family-friendly policies must be put in place to revive the value of filial piety. But this suggestion is offered with caution: any types of policies must consider the landscape of today's reality compared to the past. In today's world, adult children are faced with many challenges in meeting the needs of their aged parents. In light of today's reality, forcing adult children to be legally obligated to care for an older parent may seem unfair if no economic support is provided to them when, at the same time, adult children are struggling to meet the needs of their own family.

Recognizing the difficulty of investigating and proving the incidents of exploitation, which often occurs in private settings, the best way to address the issue is through prevention strategies at the individual level. In terms of education, participants in this study recognized the importance of advocacy in the fields of elder abuse. Almost all participants' reflections included empowering older people. This was expressed by a few participants who reported that they wish other older people will be financially capable of managing their own affairs. Financial institutions can create awareness campaigns for older people on the importance of financial literacy and managing their finances. Campaigns can also be conducted in schools to raise awareness among the younger generation on the importance of family values and of respecting the elderly. It is also important for families and older people to be informed of the consequences of reporting experiences of financial exploitation. Older people should be encouraged to report and not succumb to stigma in society. Public awareness campaigns stressing the nature, extent, and impact of financial abuse of older persons must be conducted constantly and continuously. Prevention programs that focus on information 
dissemination, outreach, education and training, and the importance of money management are vital.

One limitation of a qualitative study is that the results cannot be generalized. Based on the data, it is believed that these experiences will not be the same if a similar study were conducted in a different locality or among older persons of similar context, race, and background. This study focuses on obtaining a qualitative, in-depth understanding of older persons who experience financial abuse by family members, and only those who can converse fluently in Bahasa Melayu and in English. Optimistically, the results of this study may inform policy makers, legislators, and relevant authorities by helping them to understand how older persons give meaning to the financial abuse experience and how they deal with such incidents.

\section{Conclusion}

This investigation proved that victims' silence speaks volumes. This qualitative study formed the basis for a greater effort to elucidate the importance of legal and social protection for victims of elder financial abuse, as well as the need to find alternative solutions to legal action that preserve the family institution. A multidisciplinary approach from the health and financial sectors can improve statistics on abuse incidents. Primary health care workers and bank officers are among the first responders to identify victims of financial exploitation. Having a mandatory reporting mechanism would bring the victims directly into the system for intervention. Statistical data may be improved and eliminate the underreporting issue. Attention should focus on providing the best support systems to victims of abuse, with consideration for their living conditions and the intervention process. Under these circumstances, the old saying of "no news is good news" is not valid since existing legislation and policies force victims of financial elder abuse to remain grim and silent.

\section{Ethics Statement}

The studies involving human participants were reviewed and approved by the Universiti Putra Malaysia Ethics Committee for Research Involving Human Subjects (JKEUPM). The participants provided their written informed consent to participate in the study.

\section{Conflict of Interest}

The authors declare that the research was conducted in the absence of any commercial or financial relationships that could be construed as a potential conflict of interest. 
Table

Table 1: Participants' Socio-Demographic Profiles

\begin{tabular}{|c|c|c|c|c|c|c|c|}
\hline $\begin{array}{l}\text { PARTICIP } \\
\text { ANT }\end{array}$ & $\begin{array}{l}\text { AG } \\
E\end{array}$ & $\begin{array}{l}\text { GEND } \\
\text { ER }\end{array}$ & $\begin{array}{l}\text { RELIGION/R } \\
\text { ACE }\end{array}$ & $\begin{array}{l}\text { EDUCATI } \\
\text { ON } \\
\text { LEVEL }\end{array}$ & $\begin{array}{l}\text { EMPLOYME } \\
\text { NT STATUS }\end{array}$ & $\begin{array}{l}\text { CURRENT } \\
\text { PLACE OF } \\
\text { LIVING }\end{array}$ & INCOME \\
\hline P1 & 74 & $\begin{array}{l}\text { Femal } \\
\mathrm{e}\end{array}$ & $\begin{array}{l}\text { Islam/ } \\
\text { Malay }\end{array}$ & SPM & $\begin{array}{l}\text { Governmen } \\
\text { t pensioner }\end{array}$ & $\begin{array}{l}\text { Paid old folks } \\
\text { center }\end{array}$ & RM4,000 \\
\hline P2 & 75 & Male & $\begin{array}{l}\text { Islam/ } \\
\text { Indian }\end{array}$ & SPM & Not working & Welfare & $\mathrm{RM} 3,000$ \\
\hline P3 & 61 & Male & $\begin{array}{l}\text { Islam/ } \\
\text { Chinese }\end{array}$ & $\begin{array}{l}\text { Standard } \\
5\end{array}$ & Not working & Welfare & $\begin{array}{l}\text { RM1,000- } \\
1,500\end{array}$ \\
\hline P4 & 60 & $\begin{array}{l}\text { Femal } \\
\text { e }\end{array}$ & $\begin{array}{l}\text { Islam/ } \\
\text { Malay }\end{array}$ & $\begin{array}{l}\text { Standard } \\
2\end{array}$ & Cleaner & $\begin{array}{l}\text { Own house } \\
\text { with adult } \\
\text { children and } \\
\text { grandchildre } \\
\mathrm{n}\end{array}$ & RM1,200 \\
\hline P5 & 60 & $\begin{array}{l}\text { Femal } \\
\text { e }\end{array}$ & $\begin{array}{l}\text { Islam/ } \\
\text { Malay }\end{array}$ & $\begin{array}{l}\text { Standard } \\
1\end{array}$ & $\begin{array}{l}\text { Part time, } \\
\text { selling food } \\
\text { items }\end{array}$ & $\begin{array}{l}\text { Own house } \\
\text { with husband } \\
\text { and } \\
\text { grandchildre } \\
\mathrm{n}\end{array}$ & $\begin{array}{l}\text { RM700- } \\
1,000\end{array}$ \\
\hline P6 & 77 & Male & $\begin{array}{l}\text { Islam/ } \\
\text { Malay }\end{array}$ & $\begin{array}{l}\text { Standard } \\
6\end{array}$ & Pensioner & $\begin{array}{l}\text { Paid care } \\
\text { center }\end{array}$ & $\mathrm{RM} 2,000+$ \\
\hline P7 & 67 & $\begin{array}{l}\text { Femal } \\
\mathrm{e}\end{array}$ & $\begin{array}{l}\text { Hindu/ } \\
\text { Indian }\end{array}$ & $\begin{array}{l}\text { Standard } \\
4\end{array}$ & Not working & Welfare & $\begin{array}{l}\text { RM1,000- } \\
1,500\end{array}$ \\
\hline P8 & 86 & $\begin{array}{l}\text { Femal } \\
\mathrm{e}\end{array}$ & $\begin{array}{l}\text { Islam/ } \\
\text { Malay }\end{array}$ & $\begin{array}{l}\text { Standard } \\
5\end{array}$ & Not working & Welfare & $\mathrm{RM} 3,000$ \\
\hline
\end{tabular}

\section{References}

Acierno, R., Hernandez, M., \& Kilpatrick, D. (2010). Prevalence and correlates of emotional, physical, sexual and financial abuse and potential neglect in the United States: The National Elder Mistreatment Study. American Journal of Public Health, 100(2), 292-297.

Ahmed, A., Choo, W.-Y., Othman, S., Hairi, N. N., Hairi, F. M., Mohd Mydin, F. H., \& Illiani Jaafar, S. N. (2016). Understanding of elder abuse and neglect among health care professionals in Malaysia: An exploratory survey. Journal of Elder Abuse \& Neglect, 28(3), 163-177.

Bagshaw, D., Wendt, S., Zannettino, L., \& Adams, V. (2013). Financial abuse of older people by family members: Views and experiences of older Australians and their family members. Australian Social Work, 66(1), 86-103.

https://doi.org/10.1080/0312407X.2012.708762

Barjose, N. M., \& Aranas, M. A. (2016). Thematic analysis on older people understanding of elder abuse: Directions for theoretical development. University of the Visayas Journal of Research, 10(1). https://uvjor.ph/index.php/uvjor/article/view/118

Beaulieu, M., Crevier, M., D’Amours, M., \& Diaz, L. (2015). Financial exploitation of older women: A case analysis using the struggle for recognition theory. Journal of Elder Abuse \& Neglect, 27(4-5) 489-499. https://doi.org/10.1080/08946566.2015.1093990 
Bidin, A., \& Yusoff, J. Z. (2015). Abuse of the Malaysian elderly: An analysis on the adequacy and suitability of the Domestic Violence Act 1994 (Act 521) to protect the elderly victim. Journal of Management Research, 7(2), 71.

Brown, J. (1999). Bowen family systems theory and practice: Illustration and critique. Australian New Zealand Journal of Family Therapy, 20, 94-103.

Chane, S., \& Adamek, M. (2015). "Death is better than misery": Elders' accounts of abuse and neglect in Ethiopia. International Journal of Aging \& Human Development, 82(1), 54-78. https://doi.org/10.1177/0091415015624226

Chang, J., \& Moon, A. (1997). Korean American elderly's knowledge and perceptions of elder abuse. Journal of Multicultural Social Work, 6(1-2), 139154. https://doi.org/10.1300/J285v06n01_09

Conrad, K. J., Iris, M., Ridings, J. W., Langley, K., \& Wilber, K. H. (2010). Self-report measure of financial exploitation of older adults. The Gerontologist, 50(6), 758-773. https://doi.org/10.1093/geront/gnq054

Creswell, J. W., \& Creswell, J. D. (2014). Research design: Qualitative, quantitative, and mixed methods approaches (4th ed.). SAGE.

Creswell, J. W., \& Poth, C. N. (2018) Qualitative inquiry and research design choosing among five approaches (4th ed.). SAGE.

Deem, D. L. (2000). Notes from the field: Observations in working with the forgotten victims of personal financial crime. Journal of Elder Abuse \& Neglect, 12(2), 33-48. https://doi.org/10.1300/J084v12n02

Denzin, N. K., \& Lincoln, Y. S. (2011). The SAGE Handbook of Qualitative Research. SAGE.

Dessin, C. (2000). Financial abuse of the elderly. Idaho Law Review, 36(2), 203-226.

Dessin, C. (2003). Financial abuse of the elderly: Is the solution a problem? (Akron Research Paper No. 03-08). https://doi.org/10.2139/ssrn.461026

Dong, X., Chang, E.-S., Wong, E., Wong, B., \& Simon, M. A. (2011). How do US Chinese older adults view elder mistreatment? Findings from a community-based participatory research study. Journal of Aging and Health, 23(2), 289-312. https://doi.org/10.1177/0898264310385931

Doron, I., \& Apter, I. (2010). International rights of older persons: What difference would a new convention make to lives of older people? Marquette Elder's Advisor, 11(2).

Doron, I., Alon, S., \& Offir, N. (2004). Time for policy: Legislative response to elder abuse and neglect in Israel. Journal of Elder Abuse \& Neglect, 16, 63-82. https://doi.org/http://dx.doi.org/10.1300/J084v16n04_04

Folkman, S. (2011). The Oxford Handbook of Stress, Health and Coping. Oxford University Press.

Gilhooly, M. L. M., Cairns, D., Davies, M., Harries, P., Gilhooly, K. J., \& Notley, E. (2013). Framing the detection of financial elder abuse as bystander intervention: Decision cues, pathways to detection and barriers to action. The Journal of Adult Protection, 15(2), 54-68. https://doi.org/10.1108/14668201311313578

Harrison, M. O., Koenig, H. G., Hays, J. C., Eme-Akwari, A. G., \& Pargament, K. I. (2001). The epidemiology of religious coping: A review of recent literature. International Review of Psychiatry, 13(2), 86-93, http://doi.org/10.1080/09540260124356

Hightower, J., Smith, M. J., \& Hightower, H. (2006). Hearing the voices of abused older women. Journal of Gerontological Social Work, 46(3-4), 205-227.

Hong Kong Christian Service. (2004). Elderly Abuse. Retrieved from https://www.swd.gov.hk/doc/family/eld_abuse_rep.pdf 
Jackson, S. L., \& Hafemeister, T. L. (2011). Financial abuse of the elderly vs. other forms of elder abuse: Assessing their dynamics, risk factors, and society's response (Final report submitted to the National Institute of Justice). National Criminal Justice Reference Service. http://www.ncjrs.gov/pdffiles1/nij/grants/233613.pdf

Jackson, S. L., \& Hafemeister, T. L. (2015). The impact of relationship dynamics on the detection and reporting of elder abuse occurring in domestic settings. Journal of Elder Abuse \& Neglect, 27(2), 121-145. https://doi.org/10.1080/08946566.2015.1008085

Jervis, L. L., Sconzert-Hall, W., \& The Shielding American Indian Elders Project Team. (2017). The conceptualization of mistreatment by older American Indians. Journal of Elder Abuse \& Neglect, 29(1), 43-58. https://doi.org/10.1080/08946566.2016.1249816

Kaspiew, R., Carson, R., \& Rhoades, H. (2016). Elder abuse: Understanding issues, frameworks and responses (Research report no. 35). Australian Institute of Family Studies. https://aifs.gov.au/ sites/default/files/publication-documents/rr35- elder-abusenov18.pdf

Kemp, B. J., \& Mosqueda, L. A. (2005). Elder financial abuse: An evaluation framework and supporting evidence. Journal of the American Geriatrics Society, 53(7), 1123-1127. https://doi.org/10.1111/j.1532-5415.2005.53353.x

Knight, B. G., Kim, S., Rastegar, S., Jones, S., Jump, V., \& Wong, S. (2016). Influences on the perception of elder financial abuse among older adults in Southern California. International Psychogeriatrics, 28(1), 163-169. https://doi.org/10.1017/S1041610215000587

Koenig, H. G., Pargament, K. I., \& Nielson, J. (1998). Religious coping and health status in medically ill hospitalized older adults. Journal of Nervous \& Mental Disease, 186(9), 513-521.

Lee, H. Y., Lee, S. E., \& Eaton, C. K. (2012). Exploring definitions of financial abuse in elderly Korean immigrants: The contribution of traditional cultural values. Journal of Elder Abuse \& Neglect, 24(4), 293-311. https://doi.org/10.1080/08946566.2012.661672

Lee, H. Y., Yoon, H. S., Shin, N., Moon, J.Y., Kwon, J. H., Park, E. S., Nam, R., Kang, S. B., \& Park, K. H. (2011). Perception of elder mistreatment and its link to help-seeking intention. A comparison of elderly Korean and Korean American immigrants. Clinical Gerontologist, 34(4), 287-304. https://doi.org/10.1080/07317115.2011.573407

Lowenstein, A. (2009). Elder abuse and neglect-"Old phenomenon": New directions for research, legislation, and service developments, Journal of Elder Abuse and Neglect, 21, 278-287.

Mardan, H., Jaehnichen, G., \& Hamid, T. A. (2014). Is self-neglect associated with the emotional and financial abuse in community-dueling? IOSR Journal of Nursing and Health Science, 3, 2320-1940.

Metlife. (2010). The Metlife Study of Elder Financial Abuse: Crimes of occasion, Desperation, and Predation against America's Elders. Metlife Mature Market Institute/National Committee for Prevention of Elder Abuse/Virginia Polytechnic Institute and State University. Westport CT: Metlife Mature Market Institute.

Mihaljcic, T., \& Lowndes, G. (2013). Individual and community attitudes toward financial elder abuse. Journal of Elder Abuse \& Neglect, 25(2), 183-203. https://doi.org/10.1080/08946566.2012.712867

Miskovski, K. (2014). Preventing financial abuse of people with dementia. Alzheimer's Australia NSW. http://nsw.fightdementia.org.au/sites/default/files/20140618-NSWPub-DiscussionPaperFinancialAbuse.pdf 
Moon, A. \& Benton, D. (2000) Tolerance of Elder Abuse and Attitudes Toward Third-Party Intervention Among African American, Korean American, and White Elderly, Journal of Multicultural Social Work, 8:3-4, 283-303, DOI: 10.1300/J285v08n03_05

Mysyuk, Y., Westendorp, R. G. J., \& Lindenberg, J. (2013). Added value of elder abuse definitions: A review. Ageing Research Reviews, 12, 50-57.

Moskowitz, S. (1998). Saving Granny from the wolf: Elder abuse and neglect-the legal framework. Connecticut Law Review, 31.

Nerenberg, L., \& Goldman, A. (1999). Forgotten victims of elder financial crime and abuse: $A$ report and recommendations. The National Center on Elder Abuse (NCEA).

Pargament, K. I., Zinnbauer, B. J., Scott, A. B., Butter, E. M., Zerowin, J., \& Stanik, P. (1998). Red flags and religious coping: Identifying some religious warning signs among people in crisis. Journal of Clinical Psychology, 54(1), 77-89.

Petrusic, N., Todorovic, N., Vracevic, M., \& Jankovic, B. (2015). Financial abuse of older women in Serbia. Journal of Elder Abuse \& Neglect, 27(4-5), 410-421. https://doi.org/10.1080/08946566.2015.1094300

Phelan, A., McCarthy, S., Mckee, J., (2018). Safeguarding staff's experience of cases of financial abuse. British Journal of Social Work, 48(4), 924-942.

Price, T., King, P. S., Dillard, R. L., \& Bulot, J. J. (2011). Elder financial exploitation: Implications for future policy and research in elder mistreatment. The Western Journal of Emergency Medicine, 12(3), 354-356.

http://www.ncbi.nlm.nih.gov/pubmed/21731794

Rabiner, D. J., Brown, D., \& O'Keeffe, J. (2004). Financial exploitation of older persons: Policy issues and recommendations for addressing them. Journal of Elder Abuse \& Neglect, 16(1), 65-84. https://doi.org/10.1300/J084v16n01_04

Rabiner, D. J., O'Keeffe, J., \& Brown, D. (2005). A conceptual framework of financial exploitation of older persons. Journal of Elder Abuse \& Neglect, 16(2), 53-73. https://doi.org/10.1300/J084v16n02_05

Rabiner, D. J., O'Keeffe, J., \& Brown, D. (2006). Financial exploitation of older persons. Journal of Aging \& Social Policy, 18(2), 47-68. https://doi.org/10.1300/J031v18n02_04

Sanchez, Y. M. (1997). Distinguishing cultural expectations in assessment of financial exploitation. Journal of Elder Abuse \& Neglect, 8(2), 49-59. https://doi.org/10.1300/ J084v08n02_05

Setterlund, D., Tilse, C., Wilson, J., Mccawley, A. L., \& Rosenman, L. (2007). Understanding financial elder abuse in families: The potential of routine activities theory. Ageing and Society, 27(4), 599-614. https://doi.org/10.1017/ S0144686X07006009

Segal, M., Doron, I., \& Mor, S., (2021). Consumer Fraud: Older People's Perceptions and Experiences, Journal of Aging \& Social

Policy, 33:1,21, DOI: 10.1080/08959420.2019.1589896

Sherina, M. S., Rampal, L., \& Mustaqim, A. (2004). Cognitive impairment among the elderly in a rural community in Malaysia. Medical Journal Malaysia, 59(2), 252-257.

Sooryanarayana, R., Wan Yuen, C., \& Hairi, N. N. (2017). Alone and lonely: A case report on elder abuse in Malaysia. Journal of the American Medical Directors Association, 18(5), 447. http://doi.org/10.1016/j.jamda.2017.01.018

Tan, C. J. A., Choo, W. Y., M. Hairi, N. N., Abd. Hamid, A. I., Voices of Older Adults: Understanding the Meaning of Elder Financial Abuse and Exploitations in a Malaysian Rural Community. ASM Science Journal., 13, Special Issue 5, 2020 for APRU 2018, 156161 
Tilse, C., Wilson, J., Setterlund, D., \& Rosenman, L. (2005). Older people's assets: A contested site. Australasian Journal on Ageing, 24(Supplement), 51-156

Weiner, A. (1991). A community-based education model for identification and prevention of elder abuse. Journal of Gerontological Social Work, 16, 107-119. https://doi.org/10.1300/J083v16n03_09

Wendt, S., Bagshaw, D., Zannettino, L., \& Adams, V. (2015). Financial abuse of older people: A case study. International Social Work, 58(2), 287-296. https://doi.org/10.1177/0020872813477882

Wilber, K. H., \& Reynolds, S. L. (1997). Introducing a framework for defining financial abuse of the elderly. Journal of Elder Abuse \& Neglect, 8(2), 61-80. https://doi.org/10.1300/J084v08n02_06

World Health Organization. (2002). Missing voices: Views of older persons on elder abuse. http://whqlibdoc.who.int/hq/2002/WHO_NMH_VIP_02.1.pdf?ua=1

World Health Organization. (2015). World report on ageing and health. http://www.who.int/ageing/publications/world-report-2015/en/

Yan, E., Ko-Ling Chan, E., \& Tiwari, A. (2014). A Systematic Review of Prevalence and Risk Factors for Elder Abuse in Asia (Vol. 16)

Yunus, R. M., Hairi, N. N., Choo, W. Y., Hairi, F. M., Sooryanarayana, R., Ahmad, S. N., Razak, I. A., Peramalah, D., Aziz, S. A., Mohammad, Z. L., Mohamad, R., Ali, Z. M., \& Bulgiba, A. (2017). Mortality among elder abuse victims in rural Malaysia: A two-year populationbased descriptive study. Journal of Elder Abuse and Neglect, 29(1), 59-71. https://doi.org/10.1080/08946566.2016.1260083 